\title{
Risks of the European Reduction Program Incidence of Epidemic Parotitis Delayed Implementation in Russian Federation of WHO European Region
}

\author{
Nadejda Yuminova ${ }^{1,}$ ", Vadislav Semerikov ${ }^{2}$, Nikolaj Kontarov ${ }^{1}$, Irina Pogarskaya ${ }^{1}$, \\ Ekaterina Dolgova $^{1}$, Nina Povstanogova ${ }^{3}$ \\ ${ }^{1}$ Laboratory of Pediatric Viral Infections, Research Institute of Vaccines and Sera, Mechnikov of the Russian Academy of Medical Sciences, \\ Moscow, Russia \\ ${ }^{2}$ Department of Epidemiology and Hygiene, Perm State Medical Academy named After Academician Evgenij Antonovich Wagner of the \\ Ministry of Healthcare of the Russian Federation, Perm, Russia \\ ${ }^{3}$ Department of Pediatrics with the Course of Outpatient Pediatrics, Perm State Medical Academy Named After Academician Evgenij \\ Antonovich Wagner of the Ministry of Healthcare of the Russian Federation, Perm, Russia
}

\author{
Email address: \\ yuminova@mail.ru (N. Yuminova) \\ ${ }^{*}$ Corresponding author
}

\section{To cite this article:}

Nadejda Yuminova, Vadislav Semerikov, Nikolaj Kontarov, Irina Pogarskaya, Ekaterina Dolgova, Nina Povstanogova. Risks of the European Reduction Program Incidence of Epidemic Parotitis Delayed Implementation in Russian Federation of WHO European Region. American Journal of Health Research. Vol. 9, No. 2, 2021, pp. 34-38. doi: 10.11648/j.ajhr.20210902.11

Received: November 30, 2020; Accepted: December 24, 2020; Published: March 12, 2021

\begin{abstract}
Analyzing mumps incidence worldwide, we revealed that all European countries are endemic to this viral infection. In the Russian Federation Epidemic Parotitis (EP) was taken under control since 1981, when mass pediatric vaccination has begun, followed by introduction in 1998 of children's revaccination at the age of 6 . During four decades the EP incidence in Russia has decreased 300-400 times, mortality and a number of residual phenomena have been eliminated. In 2002 the WHO Regional Committee has adopted a program to eliminate measles, reduce congenital rubella syndrome to 0.01 per 1000 live births and the EP incidence to 1.0 or less per 100000 population by 2010. For eighteen years the program has been delayed several times and still has not reached its goals. The main goal of our study was to evaluate humoral immunity in EP in patient cohorts of different age. We also detected specific immunoglobulin levels and dynamics in people from 3 mumps foci; identified objective causes interfering the epidemiological well-being of the Russian population, despite vaccination coverage of $95-96 \%$. Our observations identified 2 risk groups with high mumps probability: subjects in age groups of 20 - 29 and 30 - 39 years old. The study demonstrated that the efficacy of vaccination, the intensity and duration of neutralizing mumps antibody retention is related directly to the personal immunological status and vaccine quality. In addition, our observations of subjects from 3 mumps foci as well as those, who we studied in our laboratory directly during the sporadic EP incidence increase, showed that stable, strong herd immunity cannot be achieved in long term only through pediatric vaccination and revaccination even with high population coverage. There always will be subjects non immune to EP. This number will grow after a certain time and result in an outbreak. The global goal is to monitor herd immunity both in Europe as a whole and in certain territories, including Russia. The main reason that the European community has not been able to reduce the EP incidence to goal point is the absence of a single international antibody standard that will allow to compare the individual defense level with the amount actually necessary for the protection, detected by standardized anti-mumps IgG testsystem. We hope WHO will hear us and under its auspices a single certified international serum standard with known antibody level in IU will be created, and make real EP protection potential assessment possible.
\end{abstract}

Keywords: Epidemic Parotitis, Preventive Vaccination, Population (Collective) Immunity, Booster Effect 


\section{Introduction}

Individuals and society as a whole should be protected from EP. If 25-30 years ago we believed that one-time vaccination forms lifelong immunity, then it became clear that such a strategy leads to the creation of a sensitive population in older age groups which was confirmed in the Russian Federation in the late 90s of the 20th century. It was recognized that vaccination of the whole population won't be achieved and among the vaccinated subjects some would not be immune since the one-time immunization program showed its limited efficacy. The second pediatric vaccination at the age of 6 years was introduced in the Russian Federation in 1998, and it changed the situation dramatically. First, the morbidity decreased among children at the age of 10, and later among 17-year old ones. However in parallel, the number of cases grew among adults, starting at the age of 20. Understanding of current epidemiological situation became possible due to the availability of data on seroconversion percentage after revaccination and assessment of intensity and duration of protective immunity in EP in different age cohorts. It became clear to many researchers that selective immunological and serological studies on a national scale should be carried out annually, involving different age groups. We observed EP herd immunity in different age cohorts, conducted constant morbidity monitoring, assessed the efficacy of mono- and combined mumps vaccines, as well as their safety and immunogenicity. The reasons for a number of vaccine failure, associated with the mumps foci appearance were also investigated.

\section{Materials and Methods}

In this study we used methods to assess the EP herd immunity, the efficacy and immunogenicity of Russian live mumps vaccines from domestic strain Leningrad-3 (L-3). Additionally, we attempted to understand the mechanism of immunological processes, occurring in humans as a result of boostering with the wild type EP virus and having different levels of anti-mumps immunity, as well as the reason for the development of primary and secondary immune response in the foci. The following serological and immunological methods were used:

1. Hemagglutination inhibition test (HAI)

2. Neutralization reaction (NR)

3. Neuraminidase activity inhibition reaction (NAIR)

4. Enzyme-linked immunosorbent assay (ELISA) antimumps IgM, IgG by Vector-Best (Russia) and ECOlab (Russia) [1].

Ethical approval for the study was obtained from Ethical Committee, Research Institute of Vaccines and Sera. Mechnikov of the Russian Academy of Medical Sciences.

We studied blood serum from employees, who were involved in the mumps vaccine production (mono- and combined vaccine) and thus have to take mandatory EP vaccination, and blood samples from three study cohorts: (1) youth national hockey team (Perm), competed in China; (2) youth tennis section, contacted with hockey team in Perm sports complex; (3) children 4-5 years old from Moscow kindergarten. We analyzed 450 blood samples from persons of age $4-60$.

\section{Results}

In Russia EP vaccination has been implemented for almost 40 years. The success of preventive vaccination is truly impressive. Almost 200 million people at the age over 39 years were vaccinated in Russia, 2500 lives were saved (taking in consideration the mortality rate from EP is 1:100 000), 3 million cases of serous meningitis and tens of millions orchitis cases (which, as we know, after 25 years can be bilateral) were prevented [2, 3]. In addition amount of serious associated conditions such as oophoritis, mastitis, pancreatitis, and subsequently type I diabetes, the number of preterm births, as well as spontaneous abortions, has decreased. Economic damage also has been reduced [4].

2019 was rather calm year for Russia: the incidence was $0.7: 100000$, the damage cost slightly more than 30000 rubles. Whereas at the beginning of $21 \mathrm{st}$ century the economic loss was estimated to 3 to 5 million rubles. In 10 months of 2020 the incidence of EP increased again fivefold despite of more than $95 \%$ vaccination and $96 \%$ revaccination coverage.

It is a known fact that in the Russian Federation before vaccination period from 200 to 300 thousand people got ill (in the former USSR it was twice times more). Vaccination has reduced the incidence of EP by 600 times and in the $90 \mathrm{~s}$ of 20st century it was already 88.5:100 000 and then in 20012008 - 1-3:100 000. In 2014 only 254 cases of EP were registered in Russia (0.8:100 000); in 2015 - 0.13:100 000; in $2016-0.76$; in $2017-3.03$; in $2018-0.7$. It seemed that in Russia we had almost reached the rate of less than 1:100 000 . However, in 2020, in 10 months, the incidence of EP increased five times compared to the same period in 2019. It is remarkably high in the North Caucasian Federal District, and this is already a trend. This is not counting the asymptomatic forms, which add $25-30 \%$.

$\mathrm{EP}$ - is the manageable infection. Vaccination is the main fighting method against it, recognized worldwide as the most powerful, safe, economic and effective preventive approach in the battle against this serious anthroponous viral infection.

The large-scale vaccination in Russia with local vaccine allowed not only to reduce the morbidity and mortality rate by 600 times $(1: 100000)$ compared to the pre-vaccination period, but also to ease the course of the disease [5]. The vaccination of Russian population is carried out with local monovalent vaccine against parotitis (1981), bivalent against measles and parotitis (2001), and starting in 2021 the trivalent vaccine against measles-parotitis-rubella will be used. All of these three vaccines contain Leningrad-3 mumps strain. Mumps strain L-3 was isolated in 1956, in 1965 it underwent 15 passages on guinea pig kidney cell culture and in 1977 was passaged 7 times additionally on Japanese Quail 
Embryos Fibroblast Cell Culture (JQEFC) at Moscow Institute of Viral Drugs (today Research Institute of Vaccines and Sera named after Mechnikov). All known American and European vaccine EP strains are prepared on the Chicken Embryos Fibroblast Cell. The use of JQEFC eliminated the risk of anaphylactic reactions to chicken protein during the development of an immediate hypersensivity reaction. It should be noted that there are 12 EP viral genotypes, circulating in the world. Strain L-3, isolated in our country in 1956 from a sick child, has been found only in Russia and now is assigned to a special group.

Russian vaccines against EP (mono- and polyvalent) turned out to be not only highly immunogenic, but also safe.

In the early $90 \mathrm{~s}$ of the twentieth century large mumps outbreaks involving people under 17 years old began to register in Russia. The children were seriously ill, there were many complications including neurological ones. Why? The answer was found shortly after and the second compulsory EP vaccination at the age of 6 years appeared in the National Calendar of Preventive Vaccinations. The epidemiological situation in the country immediately stabilized. At the begging of 21st century, in 2002, the Measles Elimination Program, reducing rubella incidence to sporadic level and congenital rubella syndrome (CRS) to 0.01 per 1000 live births, as well as EP incidence to 1 or less per 100000 till 2010, was approved in Russia. WHO/Europe initiated a serious task for all European countries to undergo territorial certification.

For EP the major purpose was to reduce the incidence. It was justified, since at that time it was too early to talk about elimination. Firstly only less than half of countries were vaccinated against EP. Secondly $25-30 \%$ of patients fell ill subclinically. Eight years later the achievements were positively significant but none of the three viral incidence target rates were reached. The strategy program was extended to 2015 , then to 2016 and finally to 2020 . But in 2019 it became already clear that it must be renewed again.

From 2017 to 2020 both sporadic and outbreak EP cases were registered in Russia [6-9]. It was mainly observed in the North Caucasian Federal District, the Republic of Dagestan and the Chechen Republic. We made following conclusion after careful analysis of the reasons leading to the outbreak. Immune response in subjects, vaccinated before 2000, was constantly boosted with wild type mumps strains by getting once or repeatedly into the infection region. Immunity developed after vaccination protected them and encountering with the mumps virus boosted their EP immune response. Thus the immunization occurs. Single or multiple EP virus exposure results in the formation of strong immune response. Repeated encounter with the virus depending on the antiparotitis immune status could lead to three possible outcomes. But before discussing these options, it is necessary to understand which anti-parotitis antibodies we are talking about. First of all, there are virus neutralizing antibodies, produced against $\mathrm{HN}$ - and F-proteins [10, 11]. The first scenario occurs when a person comes into contact with a patient with EP and has a high titer of neutralizing antibodies in the blood; they neutralize the virus, by binding to it. In literary terms: "it is easy for them to do so". We have analyzed blood samples, taken during the first days (sample 1) after contact with a sick patient and at a later time point, on 14-21 day (sample 2) by NR, HAI, NAIR and ELISA, - level of antibodies, detected in the 2nd sample usually drops by 1 2 dilutions. This indicates that the virus was already completely neutralized at the first stage of the response and viral replication was not observed. This outcome is only possible in the presence of virus neutralizing antibodies. If we consider a body of a child or a student, or a soldier (EP cases often happen in military groups) as a model, we will see immunity indicators somewhere by $2.0-2.5 \log$ lower than in highly immune ones. This is the average level of protection when the organism can contain the infection, and prevent it from replicating in the immunocompetent cells, which are usually lymphocytes. Specific immunoglobulins, mainly IgG class, neutralize the virus, and B-cells begin to create an additional defense line, producing new virus neutralizing immunoglobulins [12-15]. In this case the immune response will be implemented with the development of a secondary reply. The majority of antibodies will be IgG isotype 1. Analyzing the sample 2, we found out that there was a significant increase of antihemagglutinating, antineuraminidaze antibodies or antihemolysins. So in this scenario we see the manifestation of the boosting effect. The third alternative case has worst prognosis for the person. The titer of neutralizing antibodies is low and the virus manages to penetrate into the epithelial cells of the eyes and airways mucous membrane. The virus begins to replicate actively, primary immune response mechanism is activated. It leads to the production of various antibody isotypes: $\operatorname{IgM}, \operatorname{IgA}$ and IgG 3. We have had observed this disease dynamics in multiple patients during the mumps infection outbreaks. If the situation develops according to the 3rd option, the person becomes infected and infectious. Appereance of clinical symptoms will depend on the viral load, which is why in parotitis outbreak within a household the severity of the course of the infection is more pronounced, since the closer the contact, the more virus particulars enters the body.

The disease can develop with pronounced clinically manifestation or it may present in subclinical form. In cohort of young athletes (37 subjects, 15-25 years old), only one of the girls did not form antibodies during the observation of a group of athletes (after 1 month from the 1st sample was taken), but she possibly could have strong innate immunity cellular defense mechanism, which is also not rare.

But in 13 other vaccinated subjects, the immune response was formed according to the secondary type, with the formation of $\mathrm{IgG1}$ and a booster effect present [16].

\section{Discussion}

A similar situation is developing in the world, and even in the countries where children are vaccinated twice [17, 18]. Similar statistics has been reported both in England and the United States. Given the significant increase in EP outbreaks 
in 2010-2017, the Advisory Committee on Immunization Practices (ACIP) in the USA determined that, given the safety of the third dose, it can be recommended for use, even if previously vaccination took place twice. In Russia, in our laboratory practice, we have administered third dose of vaccine in the EP outbreak region, but it is essential to start immunization within the first 3 days of contact. Now this scheme is introduced in all regions. A comparable status was observed in the United States in the late 70s, when the incidence of measles rose rapidly. The disease had severe course with many fatalities. American colleagues, visited our institute, told us that the measles virus was detected during autopsy in almost all internal organs. In the United States the problem was solved promptly by introducing the 2 nd measles vaccination, which stopped the epidemic that had begun.

\section{Conclusion}

1. The efficacy of EP vaccination, the intensity and duration post vaccination immunity is directly related to the personal immunological profile and the vaccine quality.

2. High vaccination and revaccination coverage of $95-98 \%$ is very important for this respiratory infection. However, it is not the only requirement. Continuous herd immunity monitoring should be performed in order to determine the intensity and duration of immune defense.

3. Two main risk groups were located on the territory of the Russian Federation. These are people of $20-29$ and $30-39$ years old, having $18 \%$ seronegative in the first and $25 \%$ in the second group respectively.

\section{Recommendations}

Tracking and monitoring herd immunity are some of the main tasks for mumps incidence decrease both in Europe and worldwide. Mumps is a serious social infection. Many countries around the world that have not introduced the EP vaccination into their national calendar yet should assess negative social consequences of mumps infection for their population and the role EP vaccination in prolonging active longevity.

\section{Conflict of Interest}

The authors declare that they have no competing of interests.

\section{Acknowledgements}

We thank gratefully Irina Lavrent'eva from the Department of Experimental Virology of Pasteur Institute, Saint Petersburg, for providing us with the L-3 strain. Also we wish to express our sincere appreciation to Natal'ja Naretja from Territorial Department of the Ramenskoye Territorial Administration of Rospotrebnadzor for the Moscow Region for supplying us with the samples from EP outbreak region.

\section{References}

[1] Clinical laboratory diagnostics. National leadership in 2 volumes (2012) Edited by V. V. Dolgov, V. V. Menshikov, pp. 667-669.

[2] Yuminova, N. V. (1998). Scientific basis for improving measles and mumps vaccine prevention, Abstract of the thesis, p 44 .

[3] Yuminova, N. V., Alexander, S. K., Sidorenko, E. S. (2019). The efficacy of revaccination against EP and immunological safety, Vopr. Healthcare of Kyrgyzstan Virus. № 3, pp. 44-45.

[4] Yuminova, N. V., Kontarov, N. A., Pogarskaya, I. V. (2018). Epidemic parotitis: Clinic, epidemiology and genotypes of the virus, Healthcare of Kyrgyzstan. No. 2, pp. 102-104.

[5] Order of the Ministry of Health of the Russian Federation No. 832n dated 09.11.2012 "On the approval of the standard of specialized medical care for children with severe ES" Available at: htth: www.consultant.ru/document/cons.doc.LAW/14593912/rttza8 c72de3994f30496aOcc661ddafdaddf518.

[6] Yuminova, N. V. (2008). Vaccine prophylaxis against measles and EP and rubella: against measles viruses, EP with a double effect, Bul. Vaccinations. № 1-2, pp. 5-7.

[7] Yuminova, N. V. (2002). The current state of EP vaccination in Russia, J. Epidemiology and Vaccine Prophylaxis. No. 2, pp. 21-23. https://doi.org/10.15789/2220-7619-2011-1-77-80.

[8] Nozdracheva, A. V., Semenko, T. A., Rusakova, E. V. (2019). The state of population immunity to measles, rubella and EPI in the population of Moscow in 2016-2017, Epidemiology and infectious diseases. Act. Questions. V. 9, No. 2, pp. 31-38.

[9] Semerikov, V. V., Yuminova, N. V., Postanogova, N. O., Sofronova, L. V., Kontarov, N. A. (2020). Epidemic Mumps in Russia: Epidemic Situation, Key Challenges and Solutions, Text. Serial. Journal. Epidemiology and Vaccinal Prevention. https://doi.org/10.31631/2073-3046-2019-18-6-75-80.

[10] Vaccines and Vaccinations: National Guidelines. Short edition. / Ed. Zvereva, V. V., Khaitova, R. M. (2014). GEOTAR-Media, pp. 423-431.

[11] Galazka, A. M., Robertson, S. E., Kraigher, A. (1999). Mumps and mumps vaccine: a global review, Bulletin of the World Health Organization. 77 (1), pp. 3-14. PMID: 10063655

[12] Yuminova, N. V., Kontarov, N. A., Balaev, N. A. (2011). Vaccine prophylaxis of measles, mumps and rubella: tasks, problems, realities, Epidemiology and Vaccine Prophylaxis. No. 4, p. 4044.

[13] Yuminova, N. V., Alexander, S. K., Zverev, V. V. (2002). Diagnosis of measles, EP and rubella. J. Epidemiology and Vaccine Prophylaxis. No. 2, pp. 23-25.

[14] Park, S. H. (2015). Resurgence of mumps in Korea, Infect. Chemother. Vol. 47, N1. pp. 1-11. doi: 10.3947/ic.2015.47.1.1.

[15] Hershh, B. S., Fine, P. E., Kent, W. K. (1991). Mumps outbreak in a highly vaccinated population, J. Paediatr., (2) pp. 187-193. https://doi.org/10.1016/S0022-3476(05)80726-7. 
[16] Maillet, M., Bouvat, E., Robert, N., Baccard-Longere, M., Morel-Baccard, C., Morand, P. et al. (2015). Mumps outbreak and laboratory diagnosis, J. Clin. Virol. N 62. pp. 14-19. https://doi.org/10.1016/j.jcv.2014.11.004.

[17] Cheek, J. E., Baron, R., Atlas, H. (1995). Mumps outbreak in a highly vaccinated school population: evidence of large-scale vaccination failure, Arch. Paediatr., Adolesc. Med. 149 (7): pp. 774-778. doi: 10.1001/archpedi.1995.02170200064010.
[18] Willocks, L. J., Guerendiain, D., Austin, H. I., Morrison, K. E. Cameron, R. L., Templeton, K. E. (2017). An outbreak of mumps with genetic strain variation in a highly vaccinated student population of mumps with genetic strain variation in a highly vaccinated student population in Scotland, Epidemiology and Ininfection. Vol. 145, N15, pp. 3219-3225. https://doi.org/10.1017/S0950268817002102. 